\title{
The Impact of Condition on Reproduction in Flemish Cap Cod
}

\author{
M. J. Morgan and G. R. Lilly \\ Dept. of Fisheries and Oceans, P.O. Box 5667 \\ St. John's, NL, Canada A1C 5X1
}

Morgan, M. J., and G. R. Lilly. 2006. The impact of condition on reproduction in Flemish Cap cod. J. Northw. Atl. Fish. Sci., 37: 81-86. doi:10.2960/J.v37.m560

\begin{abstract}
The impacts of fish condition on reproduction have not been examined previously for Flemish Cap cod. It is known that a substantial portion of female cod skipped spawning during the late 1970s and 1980s (Walsh et al., MS 1986) and it was speculated that this might be as a result of poor condition. The purpose of this paper was to determine if there is a relationship between condition and maturity (being an adult) in Flemish Cap cod, both male and female, and to determine if there was a relationship between condition and the probability of spawning in female cod. There was no significant effect of relative body condition $\left(K_{r}\right)$ on the probability of being an adult for either male or female cod. For males there was also no significant effect of relative liver condition $\left(L K_{r}\right)$ on the probability of being an adult. For female cod there was a significant effect of $L K_{r}$ on the probability of being an adult, after accounting for the effects of age and length. However, $L K_{r}$ accounted for only a small portion of the deviance (1\%) compared to the deviance accounted for by the combined effects of age and length $(69 \%)$. There was no significant effect of $K_{r}$ on the probability of spawning in adult females, however there was a significant impact of $L K_{r}$ with females with higher $L K_{r}$ having a greater probability of spawning.
\end{abstract}

Key words: Adult, cod, condition, skip spawning

\section{Introduction}

The probability of a fish being an adult generally increases with age and size (Korsbrekke, 1999; Morgan and Colbourne, 1999). In addition there can be effects of growth rate with fish maturing younger and/or smaller at increased growth rate (Jorgensen, 1990; Rjinsdorp, 1993; Morgan and Colbourne, 1999). Increased temperature also has been shown to lead to earlier maturation through increased growth (Alm, 1957; Sandstrom et al., 1995). There can also be an additional relationship with condition so that fish in better condition are more likely to be adults, although few studies have directly examined this aspect. Marteinsdottir and Begg (2002) found an increased proportion of adult cod (Gadus morhua) at a given size or age among those that were in better condition. Bromley et al. (2000) found that adolescent turbot (Scophthalmus maximus) failed to mature under low food rations. Morgan (2004) found that female American plaice (Hippoglossoides platessoides) with low condition were less likely to be adults. Ajiad et al. (1999) found a relationship between capelin abundance and the percentage of adult fish at age for northeast Arctic cod.

Condition can continue to exert an influence on reproduction once fish have become adults. Fish in poor condition can have lower fecundity and produce larvae that are smaller and less likely to survive (Kjesbu et al., 1991; Marteinsdottir and Steinarsson, 1998; Marshall et al., 1998). Fish in poor condition may also suffer higher post spawning mortality (Lambert and Dutil, 2000). For some fish, poor condition can mean that they will forego spawning altogether and skip one or more spawning seasons (Burton and Idler, 1987; Rideout et al., 2000).

The impacts of fish condition on reproduction have not been examined previously for Flemish Cap cod. It is known that a substantial portion of female cod skipped spawning during the late 1970s and 1980s (Walsh et al., MS 1986) and it was speculated that this might be as a result of poor condition. The purpose of this paper was to determine if there is a relationship between condition and maturity (being an adult) in Flemish Cap cod, both male and female, and to determine if female cod that were in lower condition were more likely to skip a spawning season.

\section{Materials and Methods}

Data for these analyses came from Canadian research vessel surveys of the Flemish Cap from 197885 . These surveys were conducted in January/February 
using a stratified random survey design. The Gadus Atlantica conducted the surveys using an Engel 145 bottom trawl with a small mesh liner in the cod end. All cod were measured ( $3 \mathrm{~cm}$ groupings) and most cod were examined for sex and maturity. Cod were assigned to various maturity stages based on macroscopic examination of their gonads using the maturity classification of Tempelman et al. (1978). Otoliths were extracted from a length-stratified sample (up to 25-30 specimens per $3 \mathrm{~cm}$ grouping) in 1978-82 and from virtually all fish caught in 1983-85. A length-stratified sample of cod was frozen round at sea. In 1978-82 up to 5-6 cod per $3 \mathrm{~cm}$ length-group were chosen haphazardly from the survey area as a whole for the frozen sample, and in 1983-85 up to 2 cod per $3 \mathrm{~cm}$ length-group were chosen from each of 4 Subareas. The 4 Subareas were defined by dividing the Cap east to west by the $45^{\circ} \mathrm{W}$ longitude line and north to south by the $47^{\circ} 10^{\prime} \mathrm{N}$ line of latitude. This was an attempt to spread the sampling throughout the Cap. These frozen cod were thawed in the laboratory on land for detailed observations, among which were sex, maturity, weights of whole fish, both round and gutted, and weights of various organs. Otoliths were removed for ageing.

Indices of condition were used to examine the effect of both liver and body weight on reproduction. Only fish greater than $20 \mathrm{~cm}$ were used in the calculations involving body weight because of variability in the weight measurements below this size and 1309 fish were used in the analyses. For gutted body weight the commonly used index of Fulton's $K\left(K=W / L^{3}\right.$, where $W$ is gutted body weight and $L$ is length) showed an increasing trend with body length, so an alternative index, relative $K$ $\left(K_{r}\right)$ was used. $K_{r}=W / \hat{W}$, where $\hat{W}$ is the predicted body weight from a length-weight relationship. The form of the length/weight relationship was $\log (W)=$ intercept + $\log (L)$. Separate regressions were carried out for each sex. Data for all years combined were used in the regressions. To calculate $K_{r}$ for an individual fish, its gutted body weight was divided by the gutted body weight predicted by the length/weight regression for a cod of that length and sex. The use of this type of condition index removes the problems associated with systematic change in the index across length. However, the indices produced are not comparable between sexes.

For liver weight, only fish greater than or equal to $30 \mathrm{~cm}$ in length were used because data below that length were highly variable. There were 1184 fish with liver weight data that met this criterion. There was a pattern in the residuals of the linear regression of $\log$ liver weight against log length, especially for males. A model of the form $\log (L W)=$ intecept $+\log (L)+(\log (L))^{2}$ was fit to the data, where $L W$ is liver weight. This model resulted in a significant fit for both males and females and minimized patterns in the residuals. The results of these models were used to produce an index of liver condition, $L K_{r}=L W / L \hat{W}$, where $L \hat{W}$ is the predicted liver weight from the length/liver weight relationship.

To determine if there was a significant effect of $L K_{r}$ or $K_{r}$ on the probability of being an adult, generalized linear models were used ( $\mathrm{M}^{\mathrm{c}} \mathrm{Cullagh}$ and Nelder, 1983). In these models cod were classed as either adult (1) or juvenile (0). Adult cod are those that show some evidence of maturing to spawn, spawning or having spawned in the past while juvenile cod are those that show no evidence of having spawned in the past or of maturing to spawn. All models had a logit link function and a binomial error structure. All parameters were modelled as continuous variables. Since age and length are already known to affect the probability of being an adult in this species (Ajiad et al., 1999; Korsbrekke, 1999) the significance of $L K_{r}$ or $K_{r}$ was tested by determining if there was a significant decrease in the deviance with the addition of the index to a model already containing age and length effects.

Since these analyses of the effect of condition on the probability of being adult include ages for which most (or all) of the fish are adult, this could mask any effects of condition since the maturation process has already taken place for some fish. In an attempt to account for this, analyses of the effect of $L K_{r}$ were carried out on an age by age basis for those ages over which most fish mature. For females this was ages 5 and 6 and for males ages 4 and 5. New linear length-weight relationships were calculated by age for each sex and then $L K_{r}$ calculated. Generalized linear models were used to determine the effect of length and $L K_{r}$ by age.

The percentage of females that were juvenile, spawning and skipping a spawning season (non-spawners) was calculated for different length-classes to examine the distribution of the various maturity stages across length. This analysis was based on the examination of all fish for maturity stage. Analyses of the effect of condition on the probability of spawning were conducted on a subset of cod for which there was weight information collected. Females which were skipping a spawning season (non-spawners) and which had weight information, occurred over a length range of 60-95 cm, therefore only fish in this length range were included in the analyses of the effect of condition on skip spawning. Linear lengthweight regressions, as described above, for gutted body weight were used to produce $K_{r}$ and $L K_{r}$ for spawning 
and non-spawning females. There were only 24 nonspawning females with weight information in the data set. The effect of condition was tested by using generalized linear models with binomial distribution and logit link to determine whether there was a significant effect of condition on the probability of spawning.

\section{Results}

$K_{r}$ for males ranged from 0.7 to 1.3 and for females from 0.8 to 1.3. There was no significant effect of $K_{r}$ on the probability of being an adult for either male $\left(\chi^{2}=0.5\right.$, $d f=1, \mathrm{NS})$ or female $\left(\chi^{2}=3.4, d f=1, \mathrm{NS}\right)$ cod. $L K_{r}$ for males ranged from 0.2 to 2.7 and for females the range was from 0.2 to 3.4. For males there was also no significant effect of $L K_{r}$ on the probability of being an adult $\left(\chi^{2}\right.$ $=2.1, d f=1$, NS). For female cod there was a significant effect of $L K_{r}$ on the probability of being an adult, after accounting for the effects of age and length $\left(\chi^{2}=8.9, d f\right.$ $=1, P<0.005)$. However, $L K_{r}$ accounted for only a small portion of the deviance (1\%) compared to the deviance accounted for by the combined effects of age and length (69\%). Parameter estimates from the fitted model and mean length-at-age for fish in the data set were used to estimate proportion mature at age for females with $L K_{r}$ of $0.5,1.0$ and 1.5 (Fig. 1). This range of $L K_{r}$ results in about a 0.5 year difference in age at $50 \%$ maturity from 5.5 years for fish with an $L K_{r}$ of 0.5 to 5.9 years for fish with an $L K_{r}$ of 1.5 .

When analyses were conducted on an age by age basis, there was still no effect of $L K_{r}$ on the probability of being adult for males for age $4\left(\chi^{2}=0.9, d f=1, \mathrm{NS}\right)$ or age $5\left(\chi^{2}=0.05, d f=1\right.$, NS $)$. For female cod there was a significant effect of $L K_{r}$ on the probability of being an adult, after accounting for the effect length for age 5 $\left(\chi^{2}=5.6, d f=1, P<0.05\right)$ and for age $6\left(\chi^{2}=4.5, d f=\right.$ $1, P<0.05)$. For age 5 , length accounted for $24 \%$ of the deviance while $L K_{r}$ accounted for $4 \%$ of the deviance. For age 6, length and $L K_{r}$ each accounted for only about $6 \%$ of the deviance.

There was a significant effect of length on the probability of spawning $\left(\chi^{2}=644, d f=6, P<0.001\right)$. The percentage of females that were in non-spawning condition increased from $40 \mathrm{~cm}$ to peak at $60 \mathrm{~cm}$. The percentage then declined at larger lengths with few fish greater than $90 \mathrm{~cm}$ failing to spawn (Fig. 2). A decline in percent nonspawning fish between $60-70 \mathrm{~cm}$ and $80-90 \mathrm{~cm}$ was also apparent in the subsample used to analyze the effects of condition on the probability of failing to spawn. However, analyses showed that there was no significant effect of length (or age) on the probability of spawning in this subsample. Therefore the effects of length and age were

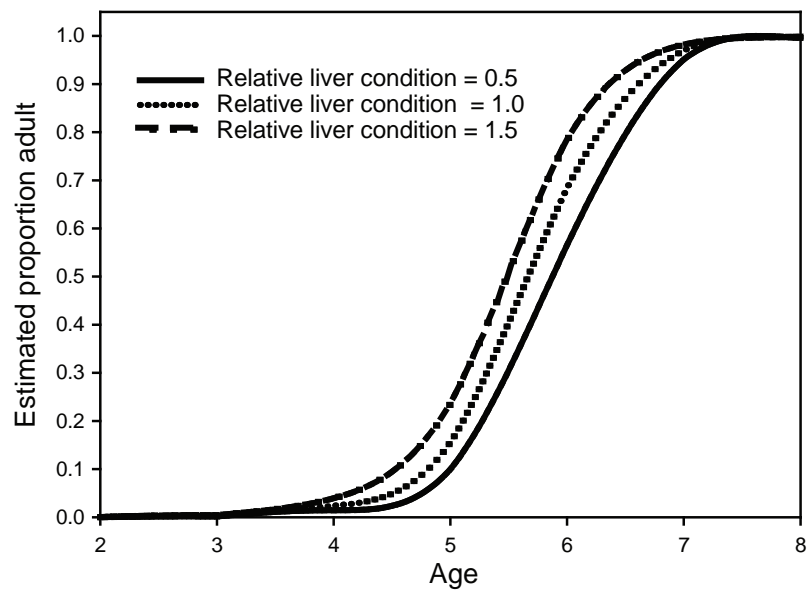

Fig. 1. Model estimates of proportion adult-at-age for female cod from Flemish Cap with different relative liver condition. Lengths-at-age used in the calculation were the means for females in the data set.

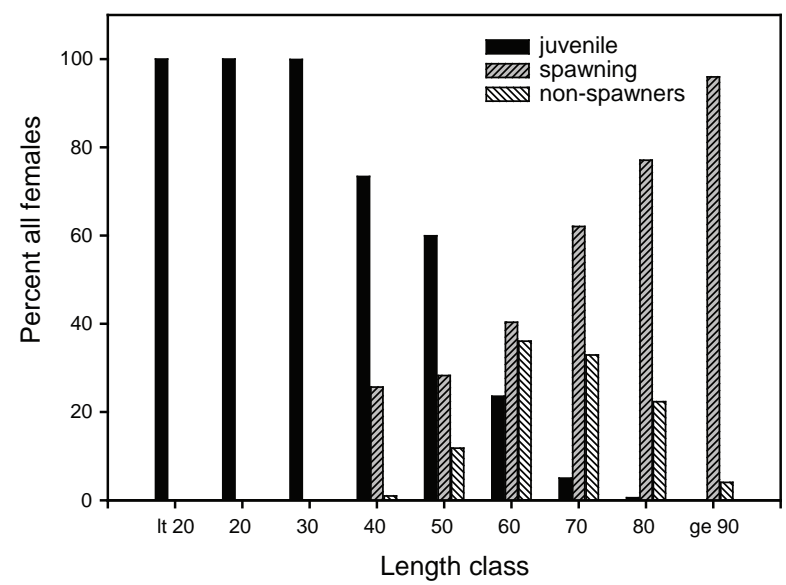

Fig. 2. The percentage of all females that was juvenile, spawning or non-spawning in different length-classes for Flemish Cap cod. The fish were divided into $10 \mathrm{~cm}$ length groupings except lt 20 grouping which were all cod that were less than $20 \mathrm{~cm}$, and the ge 90 grouping which were all cod greater than or equal to $90 \mathrm{~cm}$.

not removed before analyzing the data for an effect of condition. There was no significant effect of $K_{r}$ on the probability of spawning $\left(\chi^{2}=0.6, d f=1, \mathrm{NS}\right)$. However, there was a clear effect of $L K_{r}$ on the probability of spawning (Fig. 3) with fish with lower $L K_{r}$ being more likely to be non-spawners. This effect was significant $\left(\chi^{2}\right.$ $=17.7, \mathrm{df}=1, P<0.0001)$. Model estimates of the probability of spawning increased from less than 0.5 to 1.0 over the range of $L K_{r}$ observed in the data (Fig. 4). 


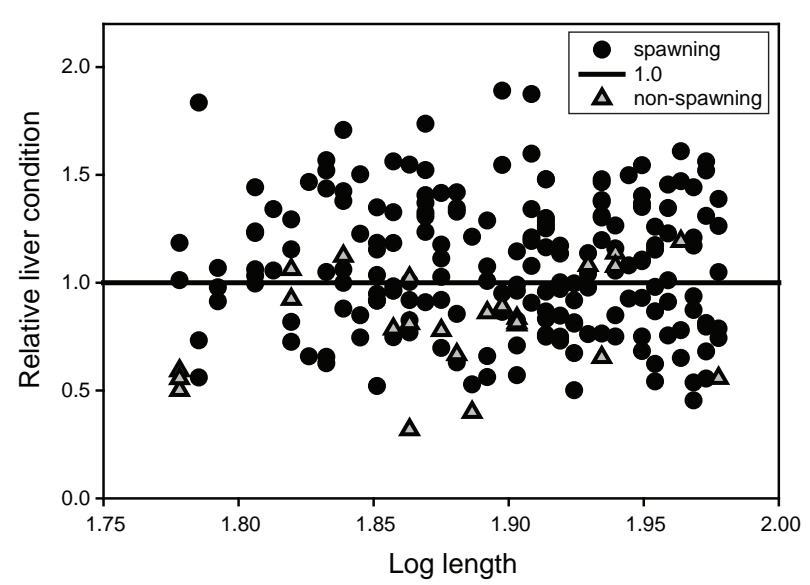

Fig. 3. Relative liver condition for spawning and nonspawning female Flemish Cap cod of different lengths. The line indicates a relative liver condition of 1.0 .

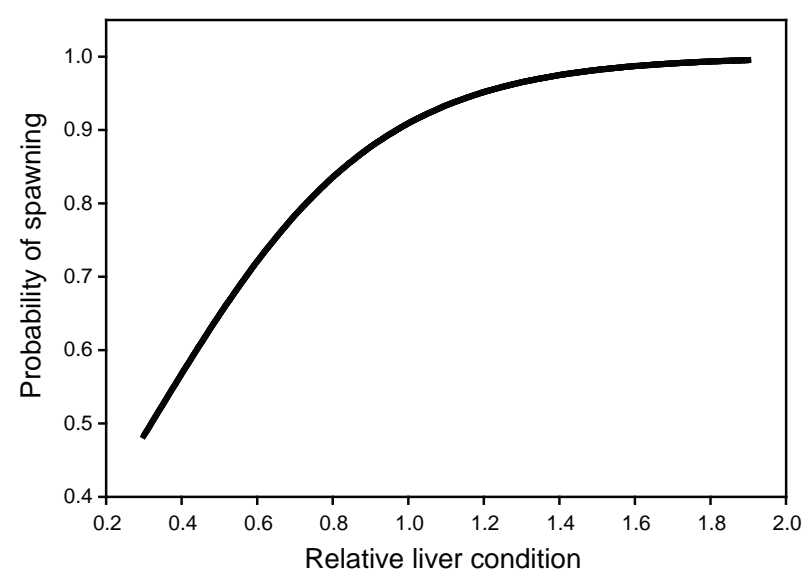

Fig. 4. Model estimates of the probability of spawning for female cod on Flemish Cap at various levels of relative liver condition.

\section{Discussion}

There was a significant positive effect of liver condition on the probability of female cod on Flemish Cap being adult. This was in addition to the positive effects of age and size. Since many fish species store energy in their liver, indices of liver condition should be good indicators of overall fish condition (Lambert and Dutil, 1997). Previous studies have also shown a positive effect of condition on the probability of being adult (Ajiad et al., 1999; Bromley et al., 2000; Marteinsdottir and Begg, 2002; Morgan, 2004). Fish make tradeoffs in energy allocation between growth and reproduction (Calow, 1985) and those in better condition may have more surplus energy to devote to reproduction and be able to mature at a smaller size and younger age.
The effect of liver condition on the probability of being adult was small compared to the combined effect of length and age. Marteinsdottir and Begg (2002) for cod and Morgan (2004) for American plaice also found that condition explained much less of the variability in the probability of being adult than length and/or age. It would seem that the main determinants of maturation are size and age with condition playing a lesser role.

In this study there was no effect of relative gutted body weight on the probability of being adult. This is in contrast to previous studies on cod and American plaice (Marteinsdottir and Begg, 2002; Morgan, 2004). However, those other studies used whole body weight in their calculations of indices of body condition. Also, both studies indicated geographic variation in the effect of body condition on the probability of being adult. Marteinsdottir and Begg (2002) attributed this to differing environmental conditions in the two areas they studied, speculating that the influence of condition might be more pronounced in areas where the environment is less conducive to growth.

There was no significant impact of either gutted body condition or liver condition on the probability of being adult in males. As with many fish species (Rijnsdorp and Ibelings, 1989; Morgan and Colbourne, 1999), male cod mature at a younger age and smaller size than females (Olsen et al., 2004). Related to this there can be differences in energy allocation between males and females when they are adults (Rijnsdorp and Ibelings, 1989; Bromley et al., 2000). The differences in the effect of condition on maturation seen here may be a result of sex specific differences in energy allocation. However, male Icelandic cod did exhibit a significant impact of condition on the probability of being adult (Marteinsdottir and Begg, 2002). It is not known whether this is the result of differences in methodology between the two studies or different responses in the two populations.

Liver condition also affected the probability that adult females would spawn. Adult females were less likely to spawn when they had lower relative liver condition. Lower condition in skip spawning females was also observed for cod in the inshore of Newfoundland (Rideout et al., 2000). Winter flounder (Pseudopleuronectes americanus) skipped spawning when kept under low ration levels during a critical period (Burton, 1994). The condition of the fish in the present study was measured close to the spawning period and it is not known what their condition level was at any other point. The assumption is made that the fish in poor condition and failing to spawn were also in poor condition during some critical period for gametogenesis. There were fish 
in similar condition to those that skipped spawning, that did not fail to spawn. It may be that individual fish make different 'decisions' regarding spawning or perhaps their condition during gametogenesis was higher than those that skipped spawning. It is probable that those cod that skipped a spawning season would spawn in subsequent years if their condition improved (Burton, 1991).

There also seemed to be an effect of length, with the probability of failing to spawn first increasing and then decreasing as size increased. The increase in the probability of non-spawning occurred across the size range over which the cod were maturing for the first time. At the length classes where virtually all females were adult, the probability of not spawning decreased with increasing size. It may be that cod are more likely to make the decision to skip spawning when energy reserves are low when they are early in their spawning history and of a smaller size.

For female cod on Flemish Cap it would appear that condition can have a substantial impact on reproduction. It plays a major role in determining if adult females will spawn in a given spawning season. It also has an influence on the probability of females being adults. Together these two effects could have important implications for the reproductive potential of the stock.

\section{Acknowledgements}

We thank all the scientific staff and ship's crew involved in the collection of these data. Eugene Murphy and Dave Downton helped with the compilation of data. Two anonymous reviewers gave helpful comments on the manuscript.

\section{References}

AJIAD, A., T. JAKOBSEN, and O. NAKKEN. 1999. Sexual difference in maturation of northeast Arctic cod. J. Northw. Atl. Fish. Sci., 25: 1-15.

ALM, G. 1957. Connections between maturity, size and age in fishes. Rep. Inst. of Freshwater Res., Drottningholm, 40: 5-145.

BROMLEY, P. J., C. RAVIER, and P. R. WITTHAMES. 2000. The influence of feeding regime on sexual maturation, fecundity and atresia in first-time spawning turbot. J. Fish Biol., 56: 264-278.

BURTON, M. P. M. 1991. Induction and reversal of the nonreproductive state in winter flounder, Pseudopleuronectes americanus Walbaum, by manipulating food availability. J. Fish Biol., 39: 909-910.

1994. A critical period for nutritional control of early gametogenesis in female winter flounder, Pleuronectes americanus (Pisces: Teleostei). J. Zool. Lond., 233: $405-415$.
BURTON, M. P., and D. R. Idler. 1987. An experimental investigation of the non-reproductive, post-mature state in winter flounder. J. Fish Biol., 30: 643-650.

CALOW, P. 1985. Adaptive aspects of energy allocation. In: Fish energetics: new perspectives. P. Tytler and P. Calow (eds.). The Johns Hopkins Unviversity Press, Baltimore, p. 13-31.

JØRGENSEN, T. 1990. Long-term changes in age at sexual maturity of northeast Arctic cod (Gadus morhua L.). J. Cons. Perm. Inter. Explor. Mer, 46: 235-248.

KJESBU, O. S., J. KLUNGSOYR, H. KRYVI, P. R. WITTHAMES, and M. GREER WALKER. 1991. Fecundity, atresia, and egg size of captive Atlantic cod (Gadus morhua) in relation to proximate body composition. Can. J. Fish. Aquat. Sci., 48: 2333-2343.

KORSBREKKE, K. 1999. Variations in maturity of haddock in the Barents Sea in relation to year-class strength, age, size, sex and area. J. Northw. Atl. Fish. Sci., 25: 37-45.

LAMBERT, Y., and J-D., DUTIL. 2000. Energetic consequences of reproduction in Atlantic cod (Gadus morhua) in relation to spawning level of somatic energy reserves. Can. J. Fish. Aquat. Sci., 57: 815-825.

MARSHALL, C. T., O. S., KJESBU, N. A. YARAGINA, P. SOLEMDAL, and O. ULLTANG. 1998. Is spawner biomass a sensitive measure of the reproductive and recruitment potential of northeast Arctic cod? Can. J. Fish. Aquat. Sci., 55: 1766-1783.

MARTEINSDOTTIR, G., and G. A. BEGG. 2002. Essential relationships incorporating the influence of age, size and condition on variables required for estimation of reproductive potential in Atlantic cod Gadus morhua. Mar. Ecol. Prog. Ser., 235: 235-256.

MARTEINSDOTTIR, G., and A. STEINARSSON. 1998. Maternal influence on the size and viability of Iceland cod Gadus morhua eggs and larvae. J. Fish Biol., 52: 1241-1258.

M CULLAGH, P., and J. A. NELDER. 1983. Generalized linear models. Chapman and Hall, London, $261 \mathrm{p}$.

MORGAN, M. J. 2004. The relationship between fish condition and the probability of being mature in American plaice (Hippoglossoides platessoides). ICES J. Mar. Sci., 61: $64-70$.

MORGAN, M. J., and E. B. COLBOURNE. 1999. Variation in maturity-at-age and size in three populations of American plaice. ICES J. Mar. Sci., 56: 673-688.

OLSEN, E. M., M. HEINO, G. R. LILLY, M. J. MORGAN, J. BRATTEY, B. ERNANDE, and U. DIECKMAN. 2004. Maturation trends indicative of rapid evolution preceded the collapse of northern cod. Nature, 428: 932-935.

RIDEOUT, R. M., M. P. M. BURTON, and G. A. ROSE. 2000. Observations on mass atresia and skipped spawning in northern Atlantic cod, from Smith Sound, Newfoundland. J. Fish Biol., 57: 1429-1440.

RIJNSDORP, A. D. 1993. Fisheries as a large-scale experiment on life-history evolution: disentangling phenotypic and genetic effects in changes in maturation and reproduction of North Sea plaice, Pleuronectes platessa L. Oecologia, 96: 391-401.

RIJNSDORP, A. D., and B. IBELINGS. 1989. Sexual dimorphism 
in the energetics of reproduction and growth of North Sea plaice, Pleuronectes platessa L. J. Fish. Biol., 35: 401-415.

SANDSTROM, O., E. NEUMAN, and G. THORESSON. 1995. Effects of temperature on life history variables in perch. J. Fish Biol., 47: 652-670.

TEMPLEMAN, W., V.M. HODDER, and R. WELLS. 1978.
Sexual maturity and spawning in haddock, Melanogrammus aeglefinus, of the southern Grand Bank. ICNAF Res. Bull., 13: 53-65.

WALSH, S. J., R. WELLS, and S. BRENNAN. MS 1986. Histological and visual observations on oogenesis and sexual maturity of Flemish Cap female cod. NAFO SCR Doc., No. 11: 1-11. 